Nordic Journal of Modern Language Methodology

\title{
Teaching American Studies to Electricians, Health Care Workers, Paramedics, Plumbers, and other High School Students in Norway: A Fulbright Roving Scholar Gets Grounded
}

By Associate Professor Colin Irvine,

- "On Wednesday you start with a small group....They are a very bright and eager bunch and their English is excellent. Then, after lunch, you will have a considerably larger class (this one is mostly boys) whose English is not as strong as the earlier students. They are electricians in training. Possibly they will like to hear what you have to say about sports in America."

- "Welcome to the tekniske skole! We are excited you are here. The students, many of whom are interested in studying mechanics and engineering, are interested and want to hear from you about roads and cars in America. They are mostly interested in cars, if that helps you prepare."

- "Thank you for your presentation on climate change and Hollywood and narrative and for your talk about the culture war and politics in America. The students were enthusiastic about both afterward. I look forward to your return next month, at which time you will teach the same topics but this time to sections of students in the more vocational tracts, athletics, plumbing, and the like. Maybe for them it would be helpful to have less academic material. Also, they may hesitate to speak up in class for discussions, but this doesn't mean they aren't interested."

\section{Introduction}


These snippets of instructions and feedback are taken from emails I have received from a few of the teachers with whom I have had the good fortune of working this fall and winter while traveling throughout Norway as a Fulbright Roving Scholar at the Upper Secondary Level. The messages speak indirectly to what has proven to be one of the most rewarding and surprising aspects of teaching in Norwegian schools, which is to say teaching vocational classes and students. Among numerous others places, I have worked with these students in schools in Trondheim, Stavanger, Mo i Rana, Roa, Finnsnes, Sandefjord, Moss, Grimstad, and Grong. In each instance I have had to deal not only with the unique challenges that attend teaching diverse groups but also with my own biases regarding the Norwegian education system, a system that differs significantly from the American one when it comes to addressing the needs of students preparing to enter into substantially different fields after high school.

In the United States, most high school students participate in basically the same generals program. And although they can take courses such as woodworking, mechanics, and accounting while in secondary school, the relatively narrow list of electives from which they have to choose is not designed to prepare them to enter particular, professional careers immediately after graduation. Accordingly, students in the American system must after matriculating either enroll in a vocational community college, a liberal arts college, a technical school, or a university (or, of course, they may choose not to pursue a formal education further). This arrangement requires that students do not and, for the most part, cannot begin preparing for their respective careers until after earning their high school diploma, which most do at age 18 or 19. Further, it should be noted that most students in the States, after entering college, do not select their major/career path until midway through the conventional 4-5 year pursuit of a bachelor's degree, at around the age of 20 or 21 .

It is these extra years - this time of fairly intense academic work and, one hopes, maturation - that represents the core difference between the Norwegian system and the one in the US. Whereas Norwegian students begin heading down their career path in their mid- to late teens, the Americans are more likely to wait until their early twenties to take those first steps in the direction of their vocation; granted, the Norwegian program as it is currently configured does 
allow for the possibility that a vocational student, for example, may change his or her mind midstream and choose instead to take classes that will, in the end, allow him or her to enroll in college; but this type of change requires that the student make relatively tough choices and formidable sacrifices, including — in some instances — taking an "extra" year of high school. One suspects that this might likely represent a deterrent to many students considering making such a change.

So, with these thoughts and concerns often at the forefront of my mind regarding the differences between the US system and the Norwegian one, I have at times entered into vocational classes and into schools that blend the traditional and vocational somewhat hesitant and even, I will admit, suspicious. This sense of something nearing skepticism has on a number of occasions been augmented by the mixed messages of teachers with whom I have worked, many of whom have warned me about the difficulties of engaging the less traditional students. Hence, when walking into those schools whose architectural layout alerts one to the blended nature of the institution - especially those with an atrium in the middle connecting the vocational classrooms on one side and the traditional ones on the other-I have worried that things might not go so well in the classroom, that I will not be able to connect with the students. However, despite my trepidations (and after making some much-needed adjustments in my lessons), I have been pleasantly surprised by my encounters with these future electricians, media experts, athletes, and others. The meetings now commonly cause me to question my assumptions about the superiority of the American system and my thoughts about these particular Norwegians students.

\section{My Vocational Background and Biases}

To begin, I could run for political office in American given the almost hackneyed nature of my educational story/career track. I am, a "first-gen"-according to college admissions vernacular — which is to say, I am a person whose parents did not graduate from a university. My mother went long enough to meet my father - one semester - and my father went only slightly longer, one year, at which point he encountered an academic advisor who altered the course of his career and, by extension, those of his children. The counselor, based on a cursory study of my father's 
transcripts and, by extension, his childhood (his mother died when he was three and he spent a considerable part of his youth in an orphanage), declared that my father would be much better off leaving school and saving his money (and the State's) by pursuing a more non-academic line of work, which he did by becoming a baker and later a carpenter and, eventually, a maintenance man at a high school.

I did not, as it turns out, follow in my father's footsteps (though I did spend ten summers and one year working for him at the school, where I learned to such valuable skills as painting, carpentry, landscaping, and welding.). Instead, after earning a bachelor's in English and history and a masters in American Studies, I ended up pursuing a doctorate in English and, eventually, taking my present position at Augsburg College in Minneapolis, Minnesota, a school with a fairly split personality: it is a liberal arts institution with one foot in the arts and the other in the professional studies programs such as nursing, education, finance, and accounting. Hence, though I am according to my business card an "Associate Professor of English and Environmental Studies," I am, in truth, more accurately a writing instructor, one who works with both the scholars in training and the budding engineers, nurses, physical education teachers, and business majors, most of whom are much more interested in the bottom line than they are in the significance of a final stanza.

Thinking I was likely leaving my past and the particulars of my present position at Augsburg behind for a time, I left for Norway in early August 2010 on what is understood in the States as a prestigious and highly sought-after Fulbright Fellowship; here in Norway it is often understood, if it is understood at all, more as "some kind of scholarship that they give to teachers who want to leave the US for a while and go somewhere else to teach and study" (this candid, unadorned description is one that a teacher gave to her colleague when trying to explain who I was and why I was there in the faculty lounge having lunch).

But, as the above excerpted emails from teachers makes clear, I was not upon arriving in the Norwegian videregående schools and classrooms in the least leaving aside my role as a professor/teacher working with a wide range of students with an even wider range of backgrounds and ambitions. That said, although my work at Augsburg and my personal 
background should have prepared me well to deliver lessons to all varieties of Norwegian students, I was initially caught off guard and thus underprepared and ineffective at times. However, after making some much-needed adjustments to my attitude and my teaching techniques, I have found to my delight that working with vocational students has enabled me to become a better student of teaching.

\section{Learning to Teach All Over Again}

During the course of this academic year spent teaching in Norway, I have come to understand that one of the primary reasons I am invited to talk with the vocational students is simply to do just that, talk (in English) with them, a point often driven home by the introductions I receive from the teachers. "Today you will hear from a real American. He will be talking with you in English," said one teacher about me to her students, a group studying electronics, "and he will be talking about — what," she turned her attention to me, "are you going to talk about?" "Cars," I said, offering an abbreviated title for the presentation otherwise labeled: "On the Road Again? The Myth of the Open Road in American Culture."

Finding common ground when it comes to teaching American Studies to vocational students is in many ways not unlike searching in the moment for the right English word or phrase. Spoiled as a college professor by the fact that I could — until relatively recently - drop references to canonical texts such as Hamlet, The Odyssey, The Adventures of Huckleberry Finn, Pride and Prejudice, and To Kill a Mockingbird, I have been forced by the situation I find myself in on a weekly basis to accept that these works and others of their class represent not a bridge but a divide between me and the students. To reach them, I have learned that I need a better means of connecting with their world. This is where pop culture, physical activities, humor, and, remarkably, singing have come in handy. While it is difficult to find a Norwegian nursing student or floral decorator-in-training enamored with Melville's Moby Dick or Faulkner's As I Lay Dying, it is even harder to find one who has not watched an episode of CSI or The Simpsons. Constructing a sort of pontoon bridge from the firm shores of Hollywood blockbusters and ubiquitous TV shows, the students and I thus work together out into less familiar territory and more challenging waters. 
Despite making these types of adjustments, though, this kind of adaptive, responsive teaching is out of step with some of the other changes I have found myself forced to make. Rather than becoming more constructivist — rather than creating more small- and large-group, student-driven activities, for instance-I have had to rely increasingly on the time-honored (and out-of-fashion) tradition of lecturing. To be sure, one of the main reasons I have been inclined to lecture more and listen less has to do with one of the primary reasons I am there in the classroom: to speak English; hence, to place the students in small groups and instruct them to speak to each otheri.e., other native Norwegian speakers of English - is counterproductive from the standpoint of the teachers. They want the students to hear "a real American" speak English. Additionally, the students' abilities with respect to speaking and writing in English often cover such a broad range that it can be counterproductive to spend too much time in a class session having them read and write in English. Hence, the conundrum: less constructivism and more performance. This means fewer games and less small-group work; and, in turn, it means more me, more lecturing and more performing. The challenge has been finding ways to lecture that invite and require the students to participate in meaningful ways throughout the presentation.

\section{The Vo-tech Classroom: Where the Rubber Meets the Road}

To illustrate these lessons learned, I turn now to a brief delineation of the two presentations I have most often been asked to give to the vocational classes. When outlining each, I will speak to the kinds of adjustments I have made in response to the students' needs and interests, some of which were expressed through questions and others through impenetrable but illuminating silence. The evolution of each presentation hopefully sheds light on the dynamic, evolving nature of my exchanges with these students and how, most importantly, they have helped me sharpen my teaching techniques while at once becoming much more grounded.

On the Road Again? The Myth of the Open Road in American Culture 
The United States has since before its inception been home to individuals fascinated with frontiers and with the idea of seeking freedom and/or fortune through movement. Many $17^{\text {th }}$ and $18^{\text {th }}$ century immigrants came to the "New World" and, over time, pushed inland from the East and later from the West, always moving into the open and allegedly available areas tied to the "wilderness"; and when the "wilderness" was mapped by Lewis and Clarke and other explorers, individuals kept moving, following the Oregon trail and other such routes and in this way living out their storied lives on the move toward something else, something more. Then, in the $20^{\text {th }}$ century, when railroads and highways crisscrossed the country, people took "to the open road" for more and different reasons, some to escape and others to find themselves or, at least, to find a little adventure. Against this historical backdrop, the lesson examines how artists have celebrated the open road in music, film, and fiction and the ways that travel narratives nurture the seemingly inborn American desire to hit the road and just keep driving. Further, the lesson discusses how, in a contemporary context that includes such issues as higher gas prices, pressing environmental problems, suburban sprawl, and traffic congestion, the car-centric American culture and the idea of "taking a road trip" are at a proverbial crossroads.

This presentation initially opened with an anthropological history of the American Dream, one that traced the links from Puritanism to industrialism to the end of the frontier and the rise of marketing and advertising. It analyzed how the automobile's birth and rise in popularity paralleled movements in America that, ultimately, made most individuals less autonomous and yet simultaneously more certain of their independence and array of options. These inconsistencies I found interesting. The students, on the other hand, did not. Still, I wanted them to understand these two main points about the role of cars and, more generally, the automobile industry in American society: first, cars affect nearly every facet of modern American life; second, this fact is not strictly the result of chance or some kind of ineluctable cultural evolution - those likely to benefit from a situation wherein cars dominate culture, business, and, in general, American lives have worked hard to shape this world into what it has and continues to become. To make these points clear to the students, I made the first of many, many changes to my PowerPoint: I created a slide that simply and boldly (in black and white) stated these two 
points. Then I repeated them. At the end of the presentation, I came back to them yet againbrilliant teaching strategy? Not really. Obvious one? Yes. Unfortunately, it was not so obvious to me until I encountered the reticence of the students.

Other adjustments were less obvious but no less important. I changed the presentation so that, rather than beginning with an historical overview beginning with the Pilgrims, the lesson begins quickly, with an exemplary "road trip" song to set the mood (Green Day's "East Jesus Nowhere" from $21^{\text {st }}$ Century Break Down), one that leads into an equally upbeat, ruckus commercial for the Dodge Challenger. This commercial features General George Washington in a period costume driving a big, black Dodge across the battle field. Flanked by several other rebel soldiers driving similar cars, Washington is shown charging toward the unsuspecting Redcoats, who rightly flee in fear. The commercial closes with an authorial voice declaring in a serious, almost somber tone, "Here's a couple of things America got right: Cars and Freedom." The students laugh at the statement (as do I), and we begin in earnest to unpack this tribute, one that takes for granted the fact that — while everyone would know enough to identify the blaring anachronisms - nobody would question the axiomatic assertion about cars and freedom, which are offered as two sides of the same coin.

My overriding goal is to help the students to do just that, to question this suggestion that cars have always and will always be equated with freedom. To that end, and in response to the indifference I was feeling from the students the first few times I gave the presentation-even those vocational students I was assured would enjoy the talk because "they love cars"-I eliminated nearly half of the text from the PowerPoints while doubling the number of slides. The new slides featured pictures, which, as the adage so rightly goes, speak a thousand words (in a universal language). And most of these pictures are of advertisements. I now present the students with print ads from the introduction of the auto back in 1870s all the way up to the 1970s (one per decade). 
Rather than putting them in small groups and having them discuss the pictures, I ask them simply to describe to the rest of the class what they see in the advertisements. Then, after they had described several, I explain the ways that their descriptions and the coded discourse specific to them contain within them evidence that they have been influenced by marketing, that they live downstream from the headwaters of the early advertising geniuses who have convinced all of us in the modern world to see the car as necessary and, on the whole, good.

The other major adjustment I made with the help of the vocational students involved addressing changes that occurred in American society related to the automobile during the 1920s. In my early attempts at teaching this lesson, I offered anecdotes illustrating the ways that US citizens historically fought hard to stem the rising tide of the auto's popularity, some going so far as to propose banning cars altogether from cities. The point I tried (and failed) to make was that there was a time in America when Americans were not in love with their cars, a time when people genuinely believed we would eventually grow weary of them and find new ways of getting around or return to the old ones. But, as I say, the remarkable fact of this now-foreign way of thinking was lost on the students.

So, in response once again to their silence, I changed the delivery of the material: I now break the class into three sections (Milwaukee, St. Louis, and New York, respectively); and I tell each group the statistics for their city related to auto fatalities and traffic congestion. Then, I give them a few minutes to come up with 3-5 solutions. Without fail, their solutions are always, invariably car-friendly. (To date, only one group in one class proposed that cars be eliminated or replaced from their city.) When I point out their bias to the students and then compare their solutions with those who lived in the early 1920s, I can almost see the flash of insight. It is rewarding, to say the least, to watch these students - the people who will design, fuel, repair, and, possibly, replace cars - appreciate this point. If ever there was a group who would benefit from understanding how to think historically, anthropologically, and sociologically about something as complex as the relationships between and among the auto industry, marketing, urban planning, and justice, it is these vocational students. 


\section{Upon Further Consideration-The Role of Sports in American Schools}

Sports of all stripes - from football to cross country skiing and from swimming to volleyballplay an important role in the life of American high schools and universities. Schools are literally built around their sports facilities; and the yearly, weekly, and daily schedules tied to academic calendars are often designed to accompany this aspect of the students' education. Against this backdrop, students discuss evidence of this collective interest in — and commitment to-amateur sports by analyzing fiction and film as well as school budgets and other materials, such as local newspapers and web links. They think through a day in the life of a typical American studentathlete, and they explore what is involved in being part of a team at the high school.

The first time I delivered this lesson was truly the first time that I wondered if maybe I should have taken after my father and become a carpenter. The blank look that strangers give each other when sitting in those facing seats on trains and subways is the look the students gave me when I called for discussion and questions. So, thus prompted once more, I eliminated much of the text from the talk, replaced it with images and videos, and, most importantly, dropped plans for group work I had deliberately built into the lesson with hopes of encouraging students to work together to arrive at shared insights. Now, after leading into the presentation with a warning-I apprise the students of the fact that "there will be some awkwardness soon, as we will all sing a few songs together"- I tell them that we will have a quiz in the form of a competition related to the topics and statistics that I cover in the PowerPoint. Then, two-thirds of the way through the talk, I ask the students (and teachers) to stand up. I explain the rules for our quiz/competition in this way: "If you think the answer to the question is, 'A,"' I tell them, "raise your arms in the air as if signaling a touchdown"; if you think it is 'B' then put your hands on your hips." To illustrate these signals, I provide on the PowerPoint slides pictures of American referees in zebra-striped uniforms doing these gestures. If a student is correct, $\mathrm{s} / \mathrm{he}$ remains standing. If not, $\mathrm{s} / \mathrm{he}$ must sit. The winner, of course, is the last person standing. In this way, the students can show what they know and hear me review in English what we have covered. 
The other such technique that I have employed and retooled out of necessity related to the need for me to speak English while keeping the students focused on the topic at hand is one that I serendipitously chanced upon. Midway through a 90-minute presentation at Tertnes VGS school near Bergen, I came back into the classroom and noted that the students, about 90 total, had begun in my absence to sing a song. It was splendid. I grabbed my camera from my bag and asked them if they would sing it again so that I could film them. They did. And louder. I could not believe it. It is hard to imagine students in American schools doing this. I incorporated this inclination of the Norwegian students (yes, I am stereotyping) into the sports presentation. Now, after breaking the class into halves in order to make it a competition, I instruct first one side and then the other to sing "The Notre Dame Fight Song" and then "The Baseball Polka!" better known as "Take Me Out to the Ballgame," the most famous sports songs in the States, the latter one sung during nearly every college and pro game in the country. Amazingly (to an American teacher), the students sing both songs loudly, and all of them are engaged and on task, something they surely were not when I taught this topic the first few times.

\section{Conclusion}

In the United States, we are fond of assuming that we are a country that values impartiality and equal opportunity above all else. But there is an inconsistency in our thinking, one that seems mostly absent here in Norwegian schools. In the US, we privilege the more "academic" pursuits over those associated with the vocational ones. When we speak of the "American Dream," for instance, and when we talk of "moving up," more often than not we are talking about moving away from manual labor and toward occupations that require more education. By association, we encourage students to do well in school so that they can "get into a good college," which, again, means one that has as its stated mission preparing individuals for elite, high-paying professions. We may not necessarily denigrate those who do manual labor, but we are nonetheless sending this message loud and clear through the structure of our educational system. Norway, by contrast, seems to be working deliberately to send a different message to its students who are electing to pursue vocational degrees and correlative occupations. 
Granted, there are Norwegian VGS schools that take pride in being "one of the best" and "most competitive" academically; but I have felt in my conversations with students, teachers, and administrators a clear, almost palpable sense that the vocational programs are equally valuable and that these students are deemed to be just as important and impressive. Proof of this respect for the less academic-oriented vocations can be found nearly everywhere one looks, of courseyou can see evidence of it in the impressive architecture, the attention to detail (everywhere!), the transportation infrastructure, the vibrant economy, and the eclectic and yet distinctive culture; but, to my mind, one of the best illustrations are the statues in front of City Hall in Oslo. Although it might be trite to say it, I truly feel that the larger-than-life, forward-looking figures are presented in a way that suggest Norway is not only proud of what that these representative builders, masons, and others did to make the country what it is, but it is also equally proud of the work that such professionals do here on a daily basis.

Finally, though I am admittedly not quite ready to abandon the American approach with its emphasis on delaying a person's important career decision for the Norwegian one that invites and almost requires students to select their path sooner, I will say that my experiences here have changed my thinking about not only the vocational classes but also my own vocation and how I go about enacting it.

Associate Professor Colin Irvine, Augsburg College, Minneapolis, Minnesota 